East Tennessee State University

Digital Commons @ East Tennessee State University

ETSU Faculty Works

Faculty Works

Spring 2017

\title{
Engaging TBR Faculty in Online Research Communities and Emerging Technologies
}

Jasmine Renner

East Tennessee State University, rennerj@etsu.edu

Follow this and additional works at: https://dc.etsu.edu/etsu-works

Part of the Higher Education Commons

\section{Citation Information}

Renner, Jasmine. 2017. Engaging TBR Faculty in Online Research Communities and Emerging Technologies. Journal of Learning in Higher Education. Vol.13(1). 33-44.

This Article is brought to you for free and open access by the Faculty Works at Digital Commons @ East Tennessee State University. It has been accepted for inclusion in ETSU Faculty Works by an authorized administrator of Digital Commons @ East Tennessee State University. For more

information, please contact digilib@etsu.edu. 


\section{Engaging TBR Faculty in Online Research Communities and Emerging Technologies}

\section{Copyright Statement}

(C) 2017 JW Press. This document was published with permission by the publisher. It was originally published in Journal of Learning in Higher Education. 


\title{
ENGAGING TBR FACULTY IN Online Research Communities and Emerging Technologies
}

\author{
Jasmine Renner \\ $2 \emptyset 16$ Fulbright Specialist Scholar \\ Professor, Department of Educational Leadership and Policy Analysis \\ Clemmer Collge of Education \\ East Tennessee State University \\ Johnson City, Tennessee
}

\begin{abstract}
The growing impact of online research communities and emerging technologies is creating a significant paradigm shift and consequently changing the current research landscape of higher education. The rise of online research communities exemplifies a shift from traditional research engagements, to online research communities using "Web 2.Ø," in which communities of researchers are the basic unit of research engagement. As institutional practices become increasingly digitized, the role of faculty, scholars, and professionals are constantly reshaped and re-negotiated. The rise and use of emerging technologies in the field of research, has the potential to significantly impact the individual researcher, their institutions and ultimately the State. The project Critical Conversations Research Network is a part of a broader initiative undertaken by the Tennessee Board of Regents Office of Academic Affairs. TBR's Critical Conversations for Jobs and the Economy is designed to complement Gov. Bill Haslam's "Drive to 55" initiative, which aims to bring the percentage of Tennesseans with college degrees to 55 percent by the year 2025. (Haslam, 2013). The initiative undertaken by TBR'S office of Academic Affairs consists of:

(a) Conversational interviewing of selected scholars and researchers across TBR institutions through video recordings of important and critical research topics that affect policy implications in the state of Tennessee, (b) an interdisciplinary journal called Critical Conversations Interdisciplinary Journal (CCIJ) dedicated to promoting dialogue on topics of importance among scholars across disciplines at TBR institutions. The journal provides a platform for critical conversations through which all disciplines can inform practice and practice can inform all disciplines, providing guidance for future public policy decisions and (c) the proposed Critical Conversations Research Network which is the focus of this paper. The goal of the Tennessee Board of Regents Critical Conversations Research Network ("TBR's-CCRN") is to connect TBR's faculty, researchers and scholars in collaboration, dialogue and engagement, about pertinent research initiatives undertaken by individuals and institutions across the state. A secondary purpose is to highlight the practical implications of research for economic and workforce development and to assist policymakers to engage in data-driven and informed decision-making.
\end{abstract}

\section{Introduction}

Online research communities (ORC) and emerging technologies (ET) have become a growing phenomenon with many and varied implications for academic use in higher education. Online research communities are a part of an emerging and developing area in research, that employs the use of cutting-edge technologies and engagement tools. The idea of an online community is not a new one. On mobile devices and in the fast paced digitized world, social interactions no longer have to be based on proximity; instead social interactions can literally occur with anyone anywhere. (Harmon, 2øø5). Online research communities have become a part of that dynamic network of access by anyone at any time. Online research communities can be defined as groups of individuals with common interests who engage in a variety of meaningful research interactions, network and engagement in an online or virtual environment. These interactions can have a major impact on strategy and operations on an individual, institutional, state and in some instances on a global level.

According to Wenger, an online community consists of three basic elements: i) first, the notion of joint enterprise, that participants shared and identify as common goals; ii) second, participants mutually engage, co-create, learn and undertake significant activities together; and iii) third, participants have a shared repertoire, a set of communal 
resources that have developed as part of their engagements. (Wenger, 1998).

Online research communities (ORCs) can be either prvate or public depending on the overall mission and goals and are typically closed password-protected communities whose members are selected based on specified profils. (Comley, 2øø8). The profiles of members of an online esserch ests, goals and a set agenda, for example frequent flyer. However, there are also instances when participation in the network are specialized experts from outside of the niche or network. Online research communities may vary in size but generally, it has been reported that the response rates of participation in an online research community (ORC) are usually higher than the open "naturally occusring" online communities. (NOOCs). (Dwyer \& Hilt 2004). These communities tend to attract a collective group of individuals who are passionate about a given subject area of particular significance in a geographic locatio or of international or global dimensions. Recruitment the community is targeted and strictly controlled and the agenda is clearly communicated at the recruitment stage. Those who wish to become a part of an online research community have to become a member via a specific site.

Online research communities can also act as an information system where members can post, comment on discussions, provide expert advice and or collaborate with each other on given topic or issue of interest. Online commun ties have become popular means for researchers and schoars to interact, collaborate and network with each other in a virtual platform. The most common forms of communication in an online setting are chat rooms, forums, e-m lists or discussion boards. (Brandtzæg \& Heim, 2øø8). Individuals also join online communities through video games, blogs and virtual worlds. In sum, online research communities are virtual communities whose members engage in meaningful and significant research and scholarly interaction and engagement via the Internet or virtual spaces. (Paragas, \& Dela Cruz, 2ø14).

Baym (2øø7) suggests that online groups are taking new forms as participants spread themselves amongst multiple Internet and offline platforms distributing themselves throughout a variety of sites in a quasi-coherent netform of distributed community poses paticularpoblens for of distributed conn

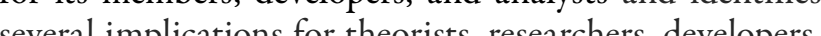
industry and independent professionals. (Baym, 2007). There are inevitably issues that can be addressed such the validity of research findings generated by participants in the community (Stafford and Gonier, 2007) and isses related with the consequential maintenance of such communities (Comley, 2øø8).

Emerging technologies (ET) as distinguished from conventional technologies (CT) is a field of technology that broaches new territory in some significant way, with new technological developments. (Soares, 1997).Some examples of current emerging technologies include educationa technology, information technology, nanotechnology, biotechnology, cognitive science, robotics, and artifcial intelligence (Soares, 1997). Emerging technologies are those technical innovations which represent progressive developments within a field for competitive advantage. (Soares, 1997).

The use of emerging technologies in higher educationa institutions is providing unique opportunities for students, administrators and faculty to use local strength and specializations on a broader scale. For example, the use of social media interfaces through computer and mobile devices has become widespread among universities and colleges with, the two most prominent cited intefaces; Facebook and Twitter. (Siefert, 2ø13).

Facebook allows users to create profiles and consequently allows those user-operated profiles to interact with each ther. It also allows the expression of interests and the discovery of commonalities between users and allows users join a community. In contrast, Twitter is a social medi interface that enables users to share a limited amount of user-generated content, quickly and easily, to an extensive number of other users. (Gesser, 2ø13).

Several research have investigated how scholars and researchers are using emerging technologies such as soci media tools to further research activities giving insight into the kinds of activites that encong .

Nolan (2ø13) for example noted that academics can no longer afford to ignore social media as it is an increasingly important vehicle for institutions to continuously build elationships and constituencies. Seifert (2013) describe how the School of Advanced Study at the University of London is using social media channels to increase awareness and engagement about the impact of individual research projects.

The New Media Consortium (NMC) Horizon Report:2014 Higher Education Edition is part of a compre. 作 impact on teaching, learning, creative inquiry and re- search around the globe in the upcoming five years. instructional practices, research, creative inquiries and (NMC Horizon Report, 2ø14). In 2ø14, the NMC project innovation that occurs at TBR institutions in the State team identified six emerging technologies or trends that of Tennessee. Currently, there are no online research will impat higher edurationg technologies or trends that of Tennessee. Currently, these are no online research wext fre year 2014 socil media is among the top emerging technologer the will inflence teching gies that willinh in the creation of the top two trends that stand out as for vision and leadership. (NMC Horizon Report. 2014 p.6). Furthermore according to the report, social media, already very well established in the consumer and entertainment sectors, is rapidly integrating into every aspect of university life; with its maximum impact expected to manifest within the next year. (NMC Horizon Report 2014 p.6). The report mentioned that for example, in the Faculty Thought Leadership Series, developed by the University of Hawaii Professional Assembly faculty across versity of Hawaii Professional Assembly, faculty across
several campuses convened to re-envision the future of the higher education teaching profession, with social media as a major component. (NMC Horizon Report, $2014 \mathrm{p} .6$ ). Recordings of the meetings were broadcast on YouTube and anyone could join the real-time discussions throug and anyone could join the real-time discussions throug
Twitter. Other examples abound in which social media is Twitter. Other examples abound in which social media is
being used by decision-makers to engage with stakeholders in new and highly cost effective ways. (NMC Horizon Report, 2014 p.7).

Social network sites have become, for most of us, part our daily routines. Consequently, individuals find themmixing contacts from different realms of life (Stutzman mixing contacts from different realms of life (Stutzman
\& Hartzog, 2ø12).Social Networking Sites (SNSs) are characterized by three distinctive features. First, they
allow individuals to create a profile within a web-based allow individuals to create a profile within a web-based
system to define their visual presence. Second, members system to define their visual presence. Second, members
can add connections with other members, creating a list can add connections with other members, creating a list of meaningful associations. Finally, users are able to navigate through such associations to access a wider network (Boyd \& Ellison, 2007). Offering a full range of features SNS incorporate aspects of the social, leisure, and inforational services that Haf the manner in which individuals communicate tain social networks.

\section{The Project}

Higher education institutions in the Tennessee Board of Regents system have a unique window of opportuniof Regents system have a unique window of opportuni-
ty to integrate and leverage the current tide of emerging technologies and online communities in profound ways. technologies and online communities in profound ways. integrated effectively into the core and fabric of current is a part of the broader initiative on Critical Conversafice of Acad amic affirs. It is also a stategic Tesponse to the need to connect faculty and students from all TBR institutions to share, engage, network and collhborate in critical conversations regarding research across the state. out TBR institutions and the State, on specific scholarly topics. TBR's CCN will consist of several thematic and sub -research collaborative groups that focus on macromajors in the TBR system as designed by Vice Chancellor Tristen Denley. Thematic or macro-major research networks would consist of temporary collaborative groups of scholars, researchers and faculty networking, sharing and disseminating pertinent research information in their respective fields and working on a specific research topics primarily through virtual communications at TBR'sCCRN. TBR's -CCRN participants will comprise of faculty researchers, administrative staff who are also active researchers and scholars from across TBR institutions in the State of Tennessee. TBR's-CCRN participants will stimulate collaborations or otherwise identify promising directions in research areas of significance research for economic and workforce development in Tennessee. Priority products for the research network include substantive reports that integrate the state of the knowledge in Tennessee and set forth promising research directions.

Goals of the Tennessee Board of Regents Critical Conversations Research Network

The goals of TBR's-CCRN are to:

1. Connect TBR's research Faculty, scholars across the state of Tennessee and encourage them to engage, network and collaborate in critical conversa tions regarding pertinent research and findings.

2. Maintain a proactive and sustainable research network that connects talented scholars and researchers across TBR institutions utilizing virtual communication tools and social networking platforms

3. Connect and engage researchers, legislators and decision makers to engage, network and collaboate in critical conversations that inform decisionmaking across the state A goal of TBRs- CCRN is to advance research throughsynthesize knowledge, examine the state of research, and 
4. Demonstrate the practical implications of research for economic and workforce dev

5. Address empirical questions that will increase the understanding of fundamental educational, scientific, technological and social issues that will yied significant improvements in policy and practice.

6. Showcase the practical implications of research for economic and workforce development and to hetp policymakers make decisions

7. Supports interdisciplinary research approach and initiatives on topics related primarily to
Health sciences, Education, STEM, Social sciencHealth sciences, Education, STEM, Soci
es, Humanities, Business, and the Arts.

\section{Project Concept}

Professor Mike Thelwall in his contribution to the Research Trends Newsletter $2 \varnothing 14$ on "A Brief History of Altmetrics" noted:

No one can read everything. We rely on filters to make sense of scholarly literature, but the most traditional filters are being swamped. The growth of new online scholarly

tools allows us to make new filters. These altmetrics reflect the broad, rapid impact of scholarship in this burgeonin ecosystem. We call for more tools and research besed (Thelwall, 2014). Traditional research is at crossroads for institutions of higher education and educational boards statewide and nationally. Figure 1 below vividly demonstrates and outlines some aspects of tunsition and change that is occurring some aspects of trans-

Market research companies have used online polls fo several years to collect quantitative data but the development of online research community tools such as discussion forums, blogs or social networks to collect data are more recent but rapidly expanding phenomena (Harmon $2065)$. With the introduction of online research communities and the infusion and integration of emerging technologies, opportunities abound to move the current state of research across TBR institutions to a more dynamic synergistic and inclusiveness making adequate and effec tive use of emerging technologies.

TBR's prototype CCRN design concept focuses on the development, utilization and diffusion of emerging technologies into new application areas such as online research networks. TBR's prototype CCRN concept is based on the opportunity model that facilitates the tran-

Research at Crossroads

Image Adapted from TBR's 2014 Maxine Smith Fellowship

Presentation By Dr. Jasmine Renner On:

"Engaging Tbr Faculty In Online Research Communities And Emerging Technologies."
Research At Crossroads

Research - Old

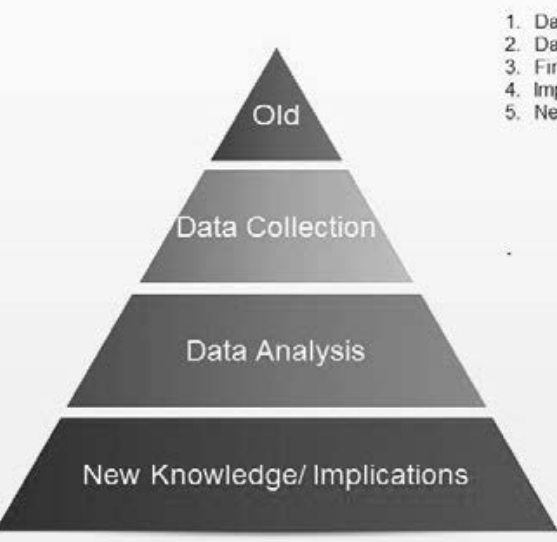

Traditional Format
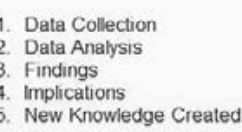

W Knowledge/ Implications
Research - New

Emerging Technologies

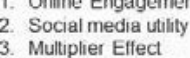

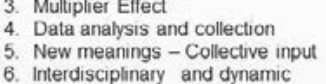

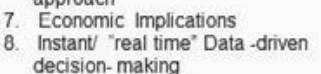

sition from the current status quo of traditional research dyn stic methods to a new dynamic platfor of engent and developed utilizing the NING sofware and a conces map adopted from the Fulbright Minds Social Enrepre neurship online research community. With over 2 aillion communites cered to date, Ning is the word's hirgest and web sites. Founded by Marc Andreessen and Gin Banchini in 2004 , Ning was acquired by Mode Media Corporation (formerly Glam Media Inc) in December 201 to bring together Ning's world-class social-native techno-ogy to help consumers and brands create and engage with passionate social communities across all digital mediums. (Ning, 2014). Ning's unique online communities features and tools includes publishing tools, community features, social integration, smartphone and tablet-ready platforms, custom design and URL and privacy moderation

In the concept development phase, I chose to use Salmon's consider the role of participants and moderators in the SaaS platform for deploying vibrant social communities controls. (Ning, 2ø14). 5 Stage Model for e-moderation as a mechanism for con-

roposed prototype research network (Salmon, 2øø4). hilst this model was developed with learning comminties in mind, it has since been wed in a number of ther ways to structure online communication processes (Lynch, Heinze, and Scott, 2øø9) and offers practical advice on the use of online communication (Chowcas, 2005 Moule, 2007). Figure 2 below, illustrates Salmo 5-Stage Model for e-moderation.

This model of online community building and facilitation describes a five-stage process mapping the different stages of engaging participants using online conmication technology. In the figure demonstrating the model the level of engagement is indicated by the interactivity column (far right hand side) and the darkness of the color Engagement starts from stage 1 "Access and motivation" and progresses up to stage 5 "Development." Each of the stages is subdivided into two triangles representing the roles of the e-moderator and the technical support staff. These roles vary at each stage.

The first stage of the 5 Stage Model is concerned with accessing the system, when participants are issued with ac-

FIGURE 2

ADAPTED FROM SALMON'S 5 STAGE MODEL FOR E-MODERATION (C) COPYRIGHT 2004, ALL RIGHTS RESERVED.

PERMISSION OBTAINED FROM AUTHOR FOR REPRODUCTION AND USE FOR EDUCATIONAL PURPOSES.

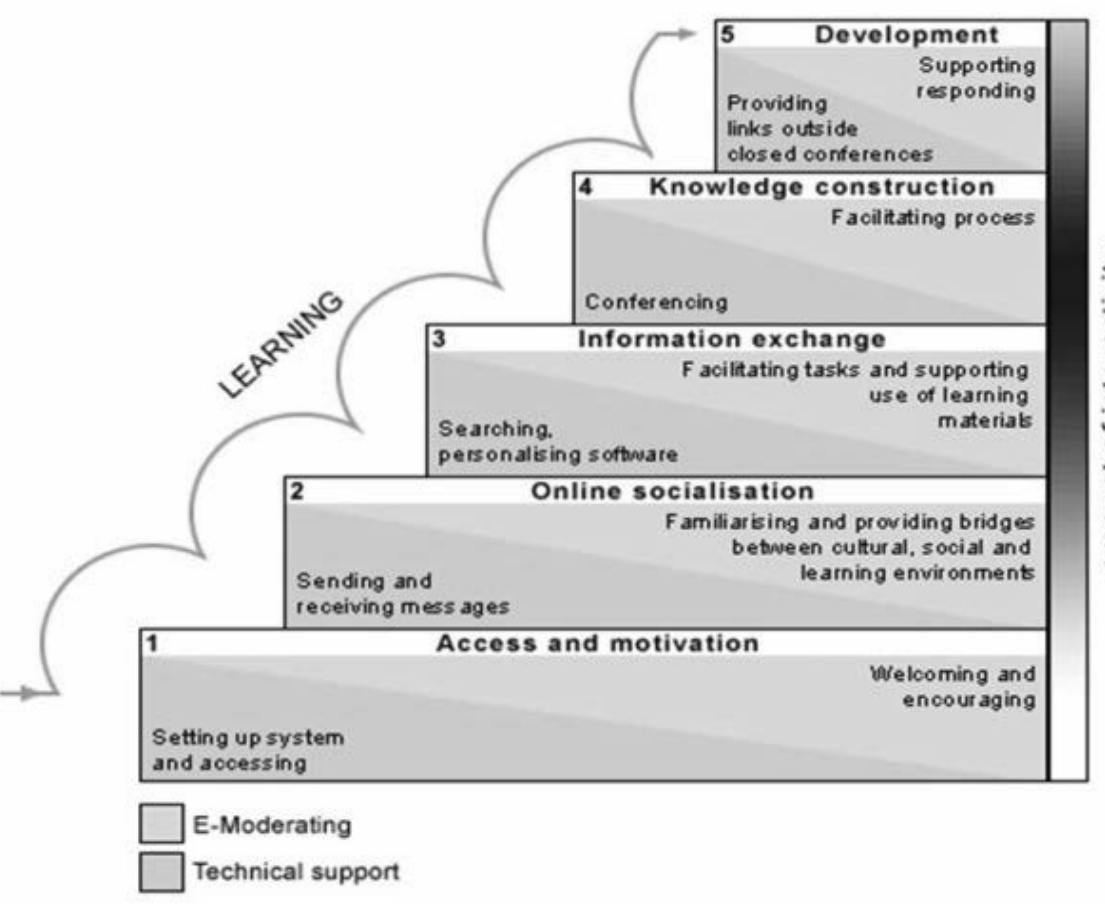

Journal of Learning in Higher Education 
by the e-moderator. The second stage focuses on online search that informs policy - and data informed decisionsocialization of the participants in the community; they making.

are encourage to familiarize themselves with the ment and socialize with others. The information exchange stage puts more emphasis on interaction and engages participants with the materials. The final two stages are where the participants should already be familiar with their environment and thus are able to proceed with knowledge construction and development.

\section{BRR's Critical Conversation}

\section{Research Network-Nodes}

Organization-The prototype CCRN will utilize and mi ror Vice Chancellor Tristen Denley designation and categorization of macro-majors utilized across TBR's insticapital and information and provides a deliberate strategic and systematic filter for organizing research information across fields for TBR institutions in the State of Tennessee. The list below provides a cursory categorization of macro-majors as designated by Vice Chancellor Tristen Denley.

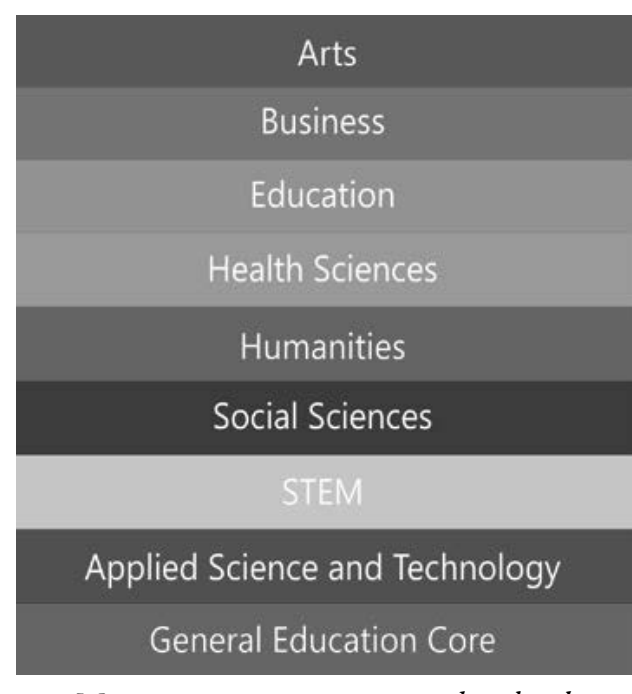

Macro-major categories as outlined in by

Vice Chancellor Tristen Denley.

The prototype nodes in the research network mirror the macro-majors categorization above and will serve as an organizational and practical tool for channeling the various kinds of research and scholarly activities that will be
generated in the network. Scholars, researcher and faculty generated in the network. Scholars, researcher and faculty
will be encouraged to participate, network and engage in
the various sub- thematic collaborative groups to harness, leverage and disseminate important and pertinent re-

\section{Project Focus}

The proposed TBR-CCRN will be the first within the Tennessee Board of Regents system. TBR's -CCRN parthe faculty, researche The project focused on designing a "prototype reserce network" that cod on designing a "prototype research TBR institutions in meaning ul research engagements.

Activities that will be undertaken by the proposed TBR's CCRN are:

Online Research Engagement

Relationships are the life blood of meaningful online communities and interaction. Participants of online communities often share information about themselves, find out what their peers are doing, , think about topics of exchange, disseminate vital information and exchanges resources and messages. TBR's prototype CCRN will facilitate the engagement of TBR researchers, scholars and faculty in online research communities and virtual groups and circles to collaborate, network, disseminate and co-create new information from an inter and multidisciplinary perspectives. This online research experience will augment already established relationships, while procal distance or other barriers to connect with each other. Darmouth found that $1 \emptyset \emptyset \%$ of surveyed universities an colleges use social media for some purpose. Faculty cited the inclusion od videos and blogs as among the most common applications of social media for instruction. Anothe survey by the Bobson research group and Pearson revealed that $7 \varnothing .3 \%$ of faculty use social media in their personal lives and 55\%use these networks specifically in professional contexts. (NMC Horizon Report, 2ø14 p.9).

\section{Dissemination of Pertinent}

\section{列}

Research paradigms are shifting to include more online communities and emerging technological tools. Scholars, devers and faculy mation, networking with peers and colleagues, learning new facts and most importantly disseminating inforng tion of their research through submission to peer reviewed journals and publishers. TBR's prototyp CCRN will in

ject a "game changer" into this model by promoting the viding spaces for individuals who are separated by physiA study conducted by the University of Massachusett art of dissemination of pertinent research findings in "real time. "In addition the opportunity for $24 / 7$ access to imOnline research communities amplify the potential for rich collaboration and instant access and dissemination of important and pertinent research findings.

Informing Data- Driven Decision-Making consumer sector since the early 1990s to inform companies about customer behaviors and preferences. There is a growing interest in using new sources of data for personalizing the research experience and for performan online activities, they leave an increasingly clear trail of analytics data that can be mined for insights. Learning analytics experiments and demonstration projects are currently examining ways to use data to modify learning strategies and processes. A recent trend in research has sought to employ analytics to improve teaching and learning. As students and faculty generate more data, there is a growing interest in developing tools and algorithms for revealing patterns inherent in those data and then applying them to the improvement of instructional systems. This in turn will have the practical effect of informing $d$ ta-driven decision making on pertinent issues of practical, policy and political implications in the State of Tennesse

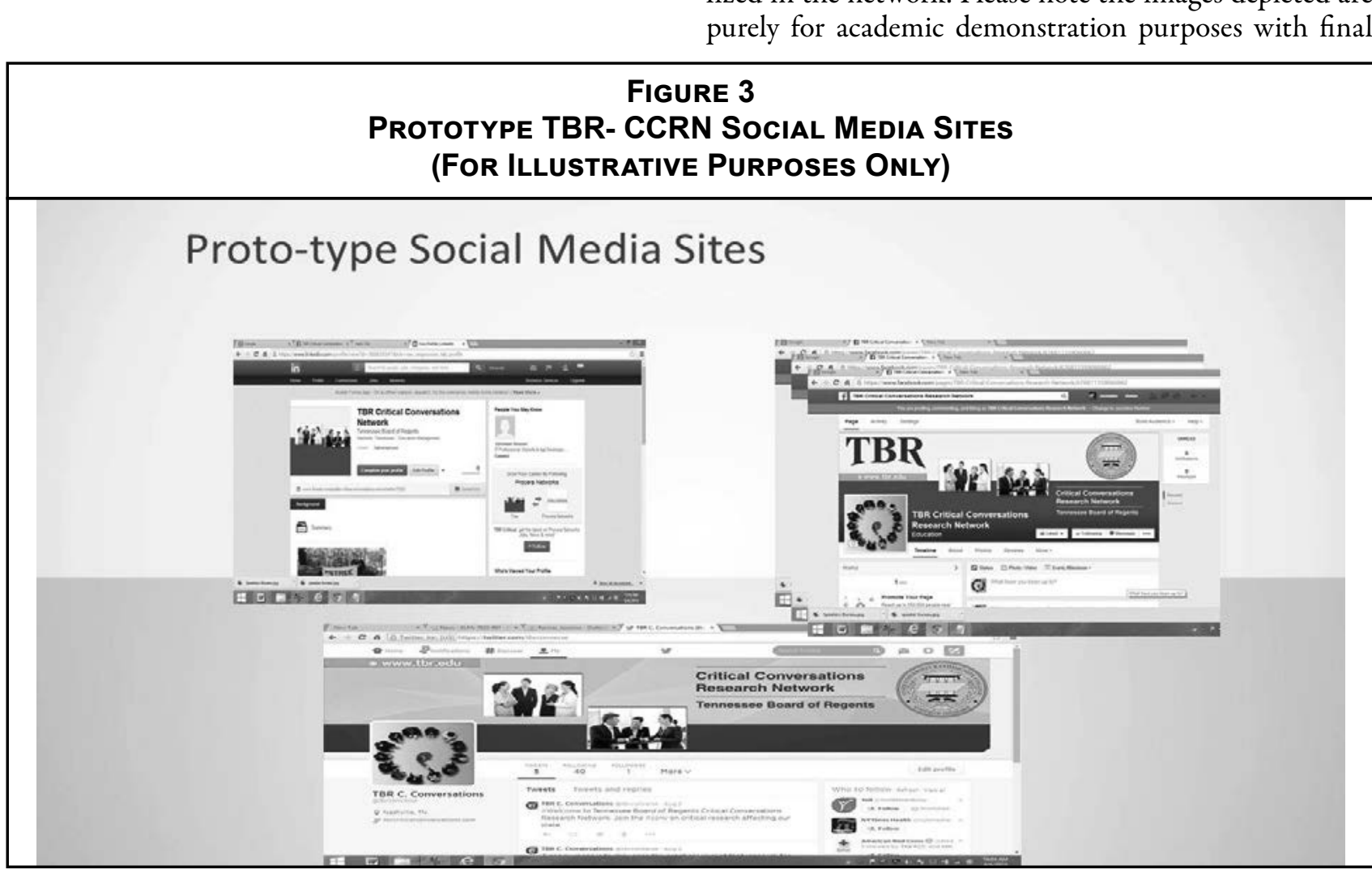

merging Technologies-The Multiplier Effect Today's web users are prolific creators of content. For educational institutions, social media enables two-way diamedia As socil netwatks contine to flour whe media. As social networks continue to flourish, educators are using them to as professional communities of practice as leaning communties and as a platform to share intersting topics and research findings. Social media is changin the way people interact, present ideas and information cars, student alimni cond the and contributions. Eduuse social media to share news general public routinely developments. The impact of these changes in scholary con eks to effectively utilize emerging tech po social media tools to harness collective research inform ion gathering and dissemination and faciliate accessbility to tha inf mation in "real time" Undertan the and scholars.

\section{Social Media Tools and TBR's-CCRN}

Figure 3 below provides a visual screen shot of a pro-typ o proposed social media tools and groups that can be utio proposed social media tools and groups that can be utipurely for academic demonstration purposes with final

FIGURE 3 portant information, data and findings is revolutionary.

Data has been measured, collected and analyzed in the measurement. As scholars and researchers participate in logues between students, prospective students, educator how social media can be leveraged for pertinent research 
images to be determined and approved by the required TB authority during the actual development phase of the network.

\section{Project Impact}

The anticipated impact of TBR's CCRN is categorized into three domains namely; the Individual, Institution and State Level. I utilized a Funnel Analysis to depict th on three distinct levels namely the Individual, Institutional and State Level.

\section{What is a Funnel Analysis?}

Funnel analysis involves using a series of events that lead towards a defined goal-from for example from user engagement in a mobile app to a sale in an eCommerce plat(the checkout process, registration, and lead generation) where users take a series of actions before reching some wort of calculate conversion rates on specific user behaviors." (cite)

The first step in a funnel analysis is to find where these funnels occur. To analyze where funnels occur, there is a need to analyze two components. 1) the current conversion rates of a particular page. The conversion rate is what percentage of users who hit the registration page are registering. 2) the current drop-off rates. At every stage in the funnel, there is an inherent potential to lose some people. But the funnels gauge and record impact of the proposed site. For example if your front page is entirely focused on getting people to try the demo, research has shown that you will likely lose at least half of your visitors before they make it to the next step.. Funnel analysis therefore helps designers to envisage impact of the proposed site (quantitatively) and to approach potential problems or challenges from the point of view of a user

Figuring out funnels from a proposed online research network is one of the most important things that can be done to increase a quantitative understanding of the proposed network and website.

Find on the facing page, a visualization of how the funnel analysis process will impact TBR's -CCRN in four different dimensions

\section{Conclusion}

Success in the field of "research" requires an understanding that a number of significant principles of engagement have changed. In a hyper connected world, information flows much faster and more freely. Institutions of learning as a result are subjected to a growing level of collective intelligence and value creation from outside the university's walls brough about by the inceas collatoris ators and students in what is now a much

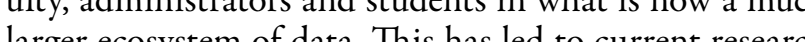
models that in production of research capital is giving way to nive line and in certain respects, collective peer production. Community based networks are becoming more prevalent than management hierarchies; where free real time global data flows a replacing traditional data collection. Therefore the generation of valuable research capital will be made possible by the generation of scholarly works cre ated through the collaboration of reserchers and schol networked economy.

Online research communities are a part and parce of this growing and potent networked economy. Online communities are powered by social power structures such as open source, crowdsourcing, specialized and thematic communities, that are proving to be more effective and efficient. William Gibson in his key note address at the O'Reilly Emerging Technoogy Conference; The Shape of Things to Come said "The future is here, it's just not widely distributed. The shape of things to come is already implicit in a thousand (t) bvious to everyone." (Gibson, 2øø8).

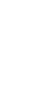

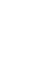
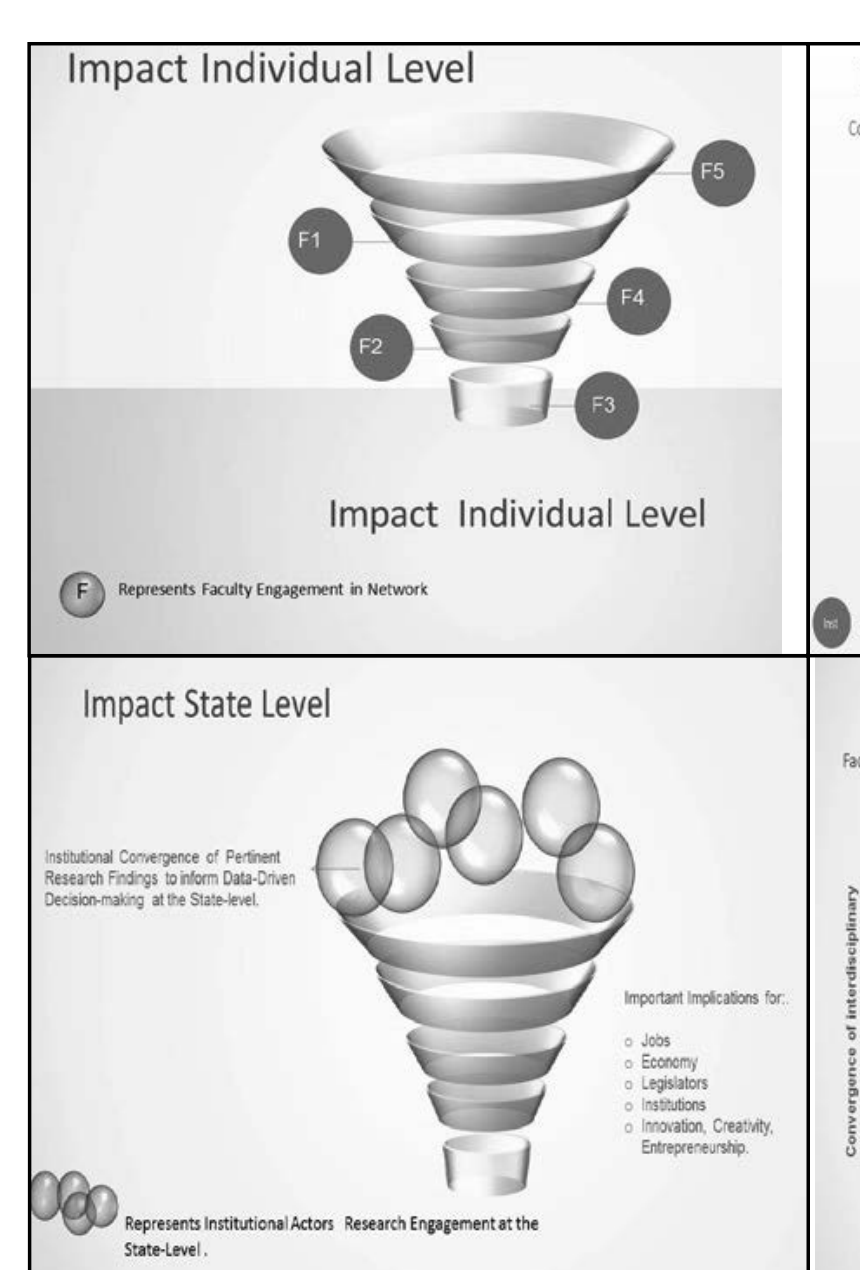

-

Overall Impact TBR Institutions and the State of Tennessee

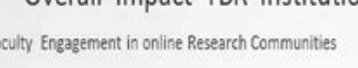

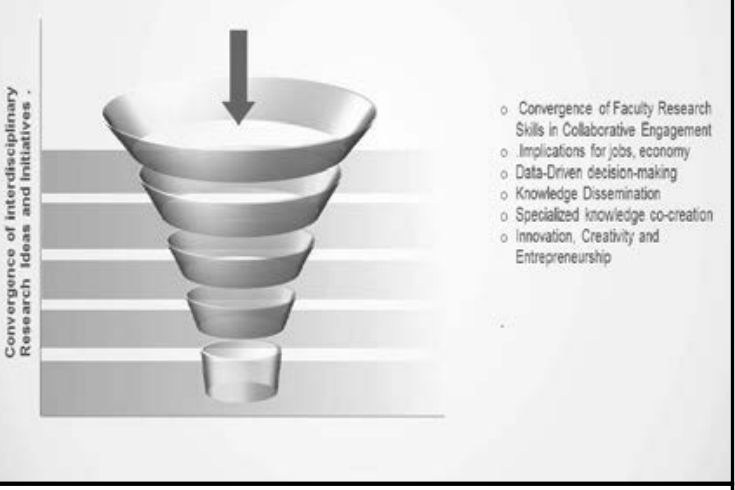

Images adapted from TBR's 2014 Maxine Smith Fellowship presentation by Dr. Jasmine Renner on: "Engaging TBR Faculty in Online Research Communities and Emerging Technologies."

References

Baym, N. K. (2øø7). The New Shape of Online Community: The Example of Swedish Independent Music org/issues/issue12_8/baym/

Bishop, J. (2øø9). Enhancing the understanding of genres of web-based communities: The role of the ecological
cognition framework. International Journal of WebBased Communities, $5(1)$

Boyd, D. M and Ellison, N.B. (2øø7). Social Network Sites: Definition, History, and Scholarship. Journal of
Computer-Mediated Communication. Volume 13, Issue 1 , pages $210-230$, October 2007.

Brandtzæg, P. B., \& Heim, J. (2øø8). User Lovalty and Online Communities: Why Members of Online Communities are not faithful. Paper presented at the 2nd international conference on Intelligent Technologies for interactive enterTAINment, Cancun, Mexico.
Brown, Nicole R. (2øø2). "”Community" Metaphors Online: A Critical and Rhetorical Study Concerning Online Aroups. . Business Communication Qmarterly $65(2) \cdot 92 . d 01.10 .11$

Comley, P. (2øø8). Online Research Communities: A User Guide. International Journal of Market Research, $5 \emptyset(5), 679-694$.

Chowcat, I. (2øø5). Models of e-learning: the importance of context. Paper presented at the ALT-C 12thInternational Conference, Manchester University, UK.

Dwyer, C., Zhang, Y., \& Hiltz, S. R. (2øø4). Using Web Analytics to Measure the Activity in a Research- OriTenth Americas Conference on Information Systems.

Gesser, C. M. (2ø13).Using Social Media in the Classroom: A Community College Perspective (Retrieved October, $5^{\text {th } 2} \varnothing 14$ from: go.nmc.org/asa). 
Hamburger, Y. A., \& Ben-Artzi, E. (2øøø). The relationship between extraversion and neuroticism and the Behavior, 16, 441-449.

Harmon, G. (2005). Online Research Category Review: Opportunities and Issues. Paper presented at the
Council of American Survey Research Organizations Data Collection Conference.

Kaldis, B. (2ø1Ø). Converging technologies. In D. Guston (Ed.), Encyclopedia of nanoscience and society. (pp. Inc. doi: http://dx.doi.org/1ø.4135/9781412972093. Lynch, K., Heinze, A., \& Scott, E. (2øø9). Scholarly L Wilson (Eds). Handbook of Research on Flectronc Collaboration and Organizational Synergy (pp. 237249). London: Information Science Reference (an imprint of IGI Global).

New Media Consortium (NMC) Horizon Report:2014 Higher Education Edition. (Retrieved September 214t, 2014 from: http:/ www.nmc.org/publications/2014-horizon-report-higher-ed).

Ning, 2ø14. (Retrieved August, 15th $2 \emptyset 14$ from www, ning.com)

Nolan, J., (2ø13). In Higher Education, Social Media Is You Job. The Huflington Past, 16 Septentor 2013.

Plant, Robert. (Jan. 2øø4). Online Communities. Technology in Society 26 (Issue 1). Retrieved

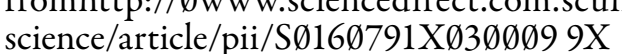

\section{APPENDIX 1}

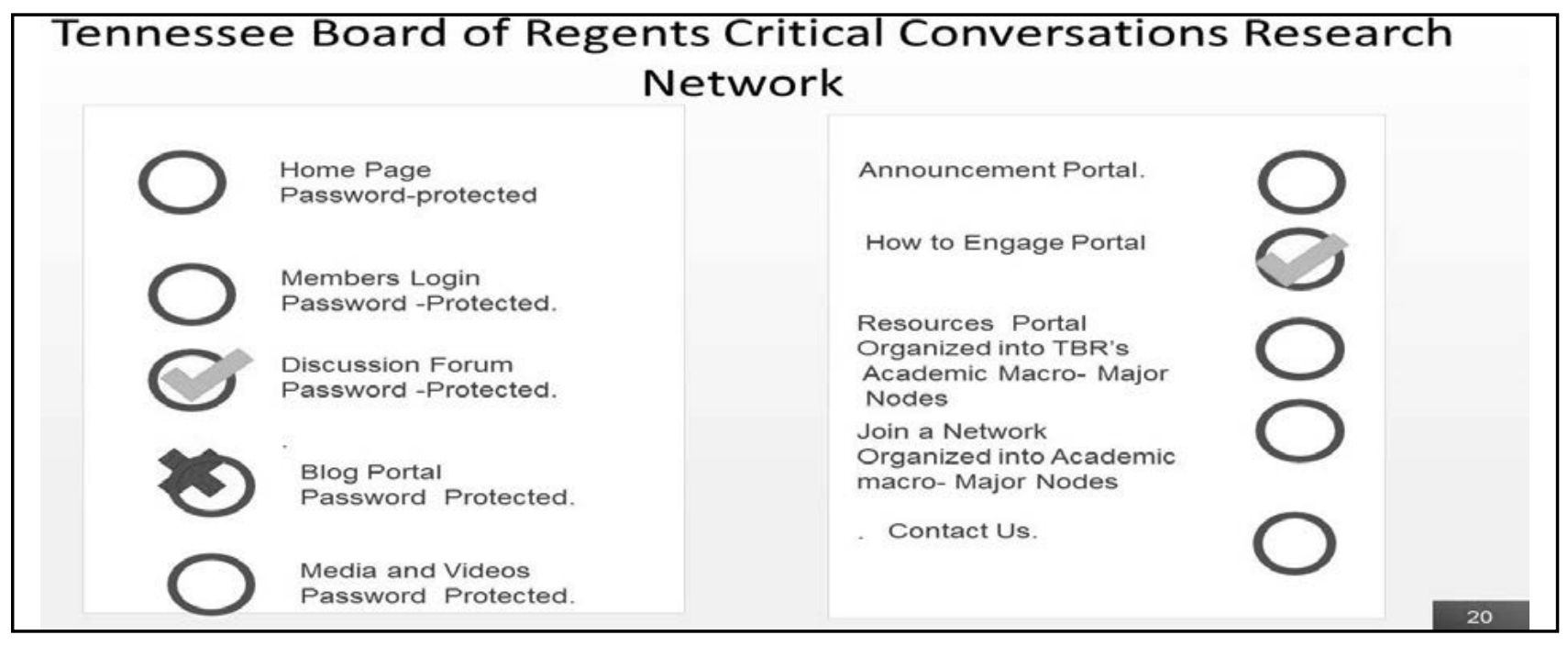

eifert, A., (2ø13). Is it Time to Start Using Social Me ia to Promote Academic Projects? School of Advanced $2 \emptyset 14$ from: go.nmc.org/time).

Seaman, J., \& Tinti-Kane, H., (2ø13). Social Media for Teaching and Learning. Babson Survey Research . Retrieved October, 5th2ø14 from: go.nmc.org/

D. D. (1997). Innovation and technology: Strategies and policies. Dordrecht: Kluwer Academic.

Stafford, T., \& Gonier, D. (2øø7). The Online Research "Bine survey sampling improve the commonly used onACM, 50(9), 109-112.

tutzman, F. and Hartzog, W. (2ø12). Boundary Regulation in Social Media. In Proceedings of ACM Con(CSCW '12). Seattle, WA 769--778 Haslam (2ø13).

Wenger, E. (1998). Communities of Practice learning as a social System. Originally published in "System

.

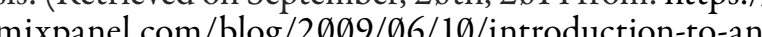

\section{TBR- CCR N'S ORganIZATION AND CATEgoRIZATION}

Network

APPENDiX 2

TBR'S- CCRN- LANDIMG PAGE PASSWORD PROTECTED

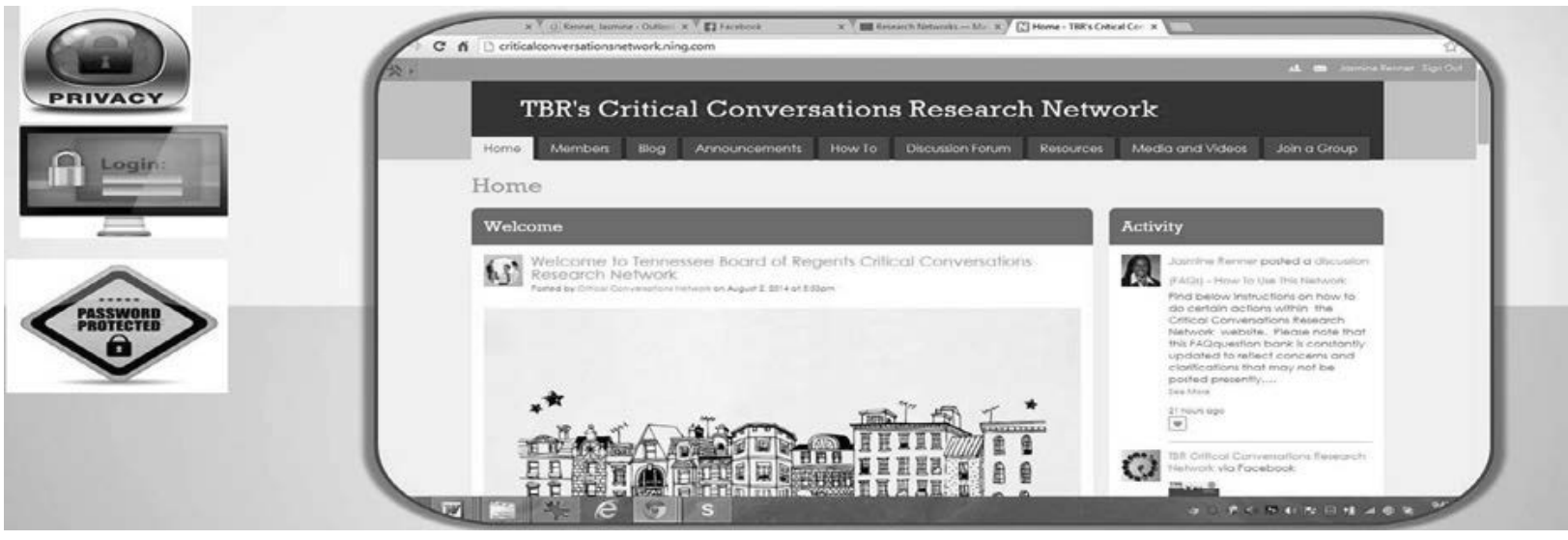

APPENDIX 3

TBR's- CCRN- Login PAge. PAssword PRotected

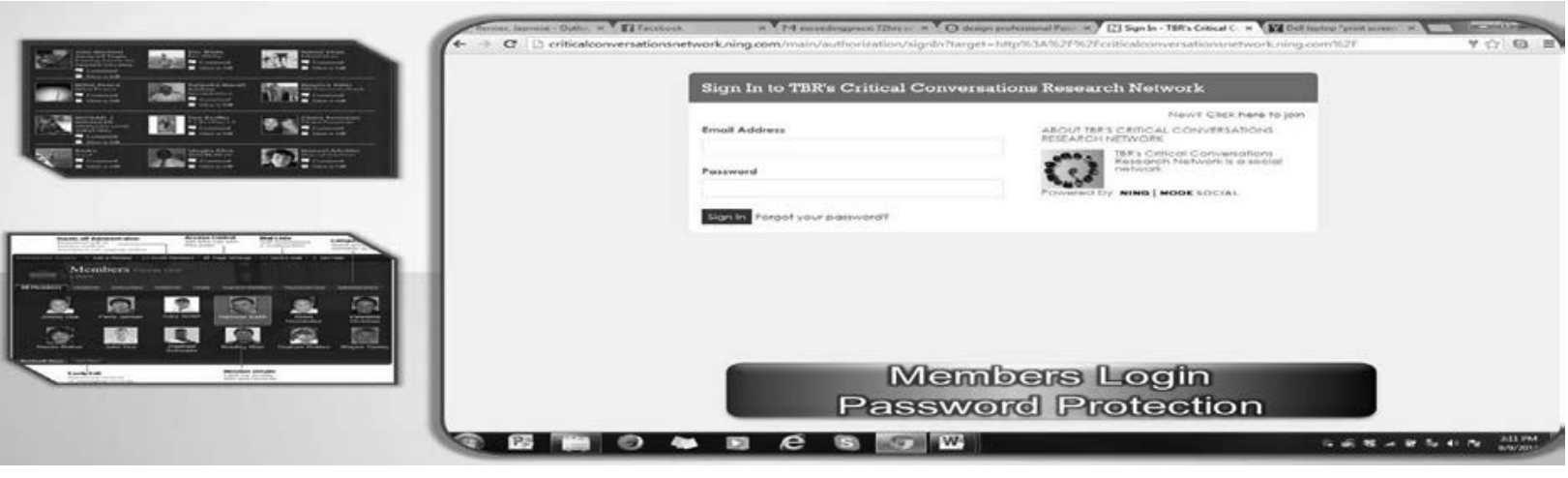

APPENDIX 4

TBR's- CCRN- Announcement Page

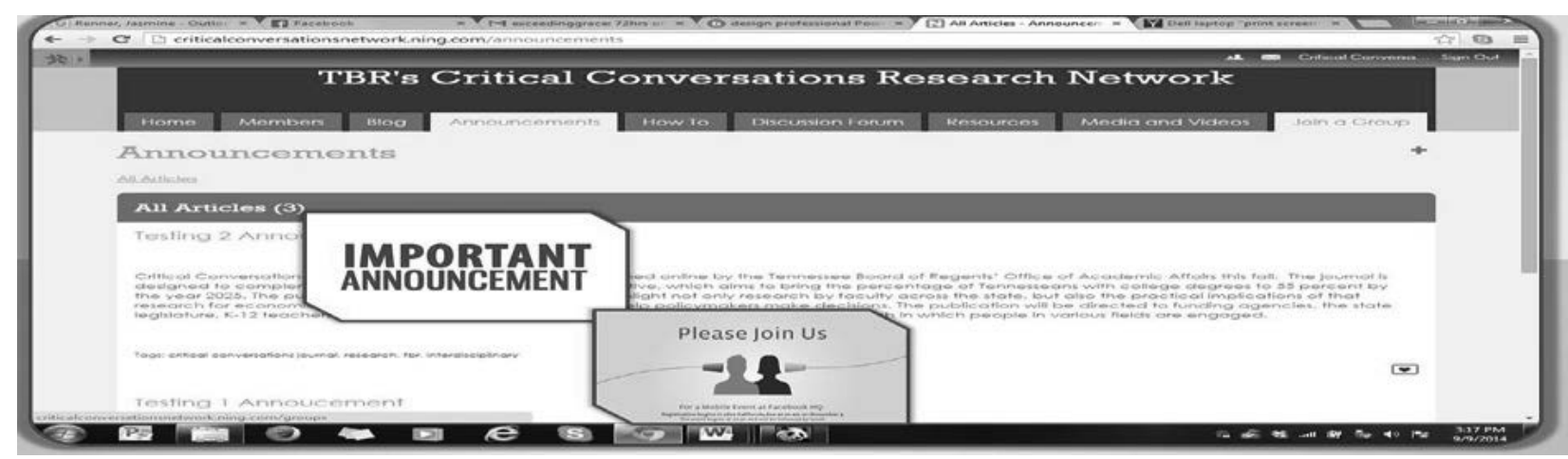

Journal of Learning in Higher Education 


\section{APPENDIX 5}

TBR'S- CCRN- FAQ PAGE

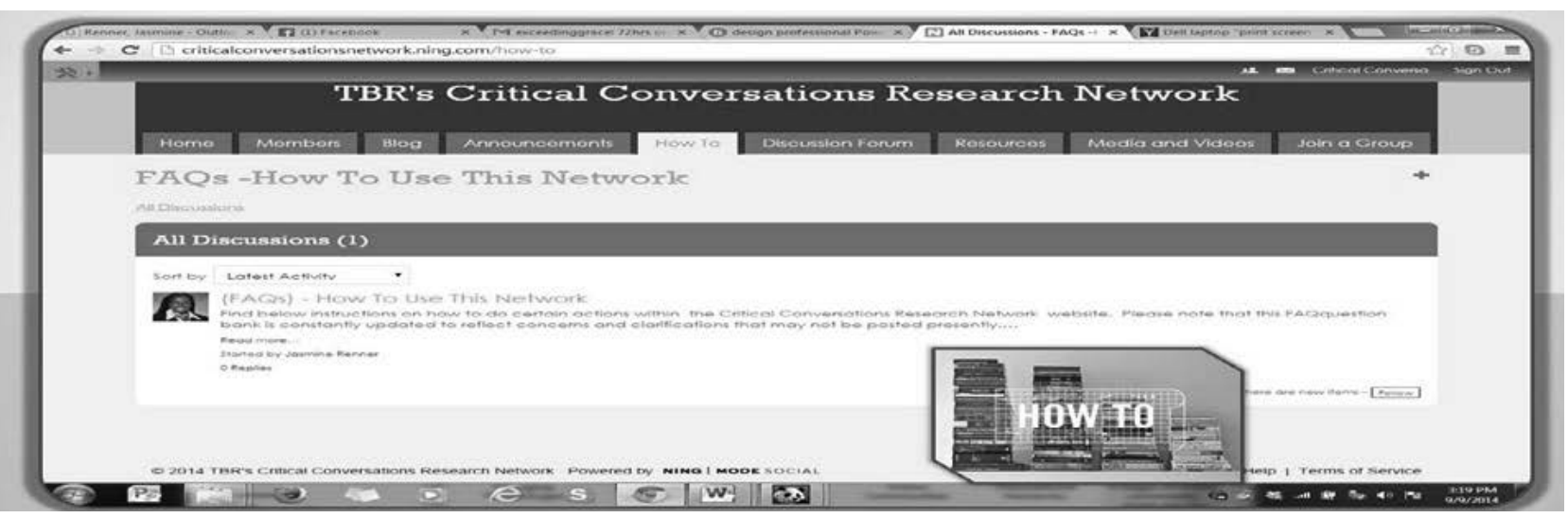

\section{APPENDIX 6}

TBR's- CCRN- Discussion PAGE

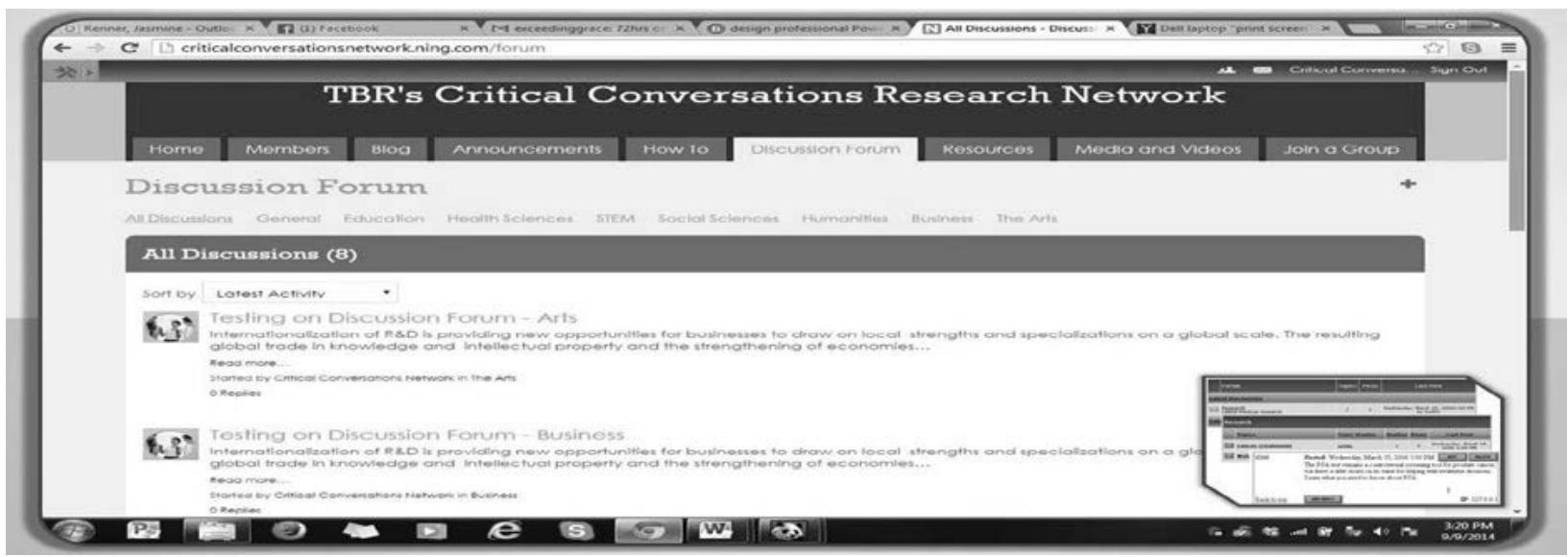

APPENDIX 7

TBR's- CCRN- REsources PAGE

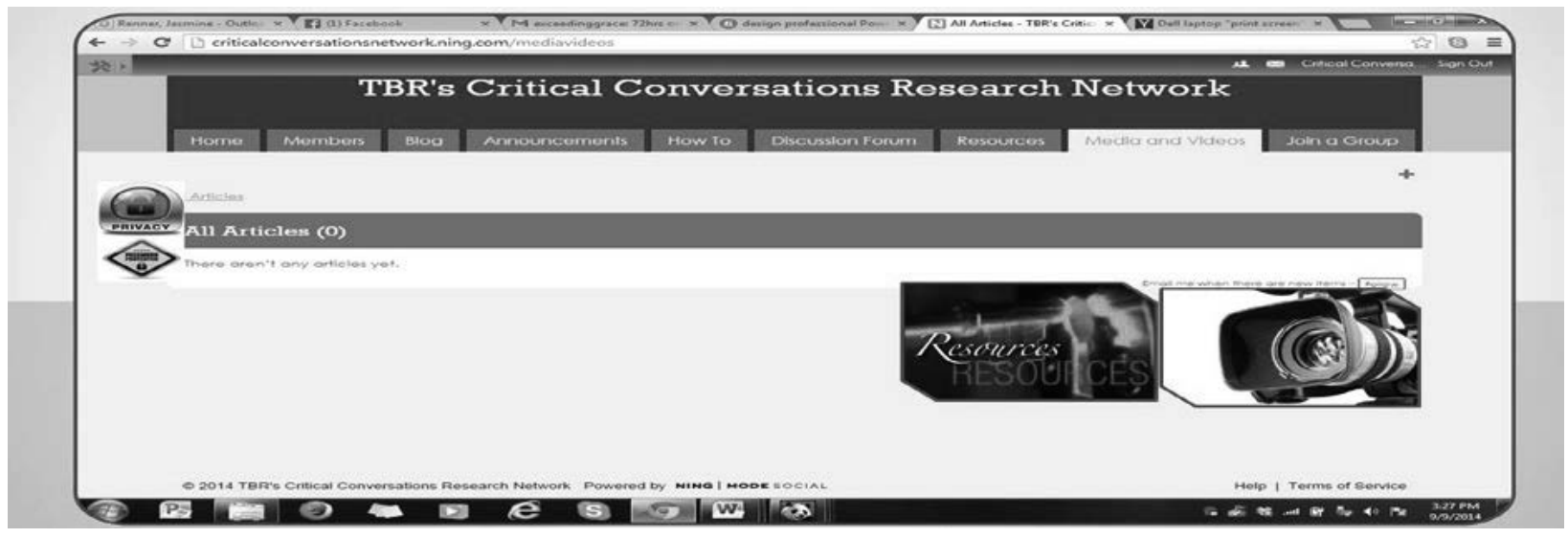

